\title{
Evaluation of maternal serum biomarkers in predicting outcome of successful expectant
}

management of tubal ectopic pregnancies

Maria Memtsa $^{1}$, Eric Jauniaux ${ }^{1^{*}}$, Béatrice Gulbis ${ }^{2}$, Davor Jurkovic ${ }^{1}$

${ }^{1}$ Institute for Women's Health, Faculty of Population Health Sciences, University College London (UCL), London, UK;

2 Department of Clinical Chemistry, Brussels Hospital University Laboratory (LHUB-ULB), Université Libre de Bruxelles (ULB), Brussels, Belgium.

* Corresponding author. Professor Eric Jauniaux, E-mail: e.jauniaux@ucl.ac.uk

Word Count: 2500.

Funding information: This study did not receive specific funding. 


\section{ABSTRACT}

Objective: To assess the value of multiple serum biomarkers for the prediction of successful outcome of expectant management in women with tubal ectopic pregnancy (TEP).

Study design: Women with a conclusive ultrasound diagnosis of TEP had a blood test to measure $\beta$-human chorionic gonadotropin ( $\beta$-hCG), progesterone, inhibin $A$, activin $A$ and high sensitivity $C$-reactive protein (hsCRP) at the initial visit. Women presenting with pain, serum $\beta$-hCG $\geq 1,500$ IU, evidence of a live ectopic pregnancy or a significant haemoperitoneum were advised to have emergency surgery. Women eligible for expectant management were followed-up prospectively until serum $\beta$-hCG declined to non-pregnant level or surgical treatment was required.

Results: A total of 93 women with a TEP were included in the final cohort. Emergency surgery was carried out in $42 / 93(45 \%)$ of women whilst $51 / 93$ (55\%) were managed expectantly. Of the latter group, $42 / 51$ (82\%) had successful expectant management and 9/51(18\%) required surgical procedure after a period of follow up. On multi-variable analysis, only higher values of serum $\beta$-hCG and progesterone at the initial visit were associated with a lower chance of successful expectant management of TEP. A one-unit increase in either variable on the log-scale was associated with an approximate 20 -fold reduction in the odds of a successful outcome.

Conclusion(s): Serum $\beta-\mathrm{hCG}$ and progesterone were significantly lower in women who had successful expectant management of TEP. Other biomarkers under consideration were not significantly different in women with successful and failed expectant management. 


\section{KEYWORDS}

Early pregnancy complications

Tubal ectopic pregnancy

Ultrasound examination

Biomarkers

Reproductive endocrinology 


\subsection{INTRODUCTION}

Tubal ectopic pregnancies (TEPs) are the most common form of extrauterine pregnancies and their management remains challenging. More than $90 \%$ of TEPs are diagnosed before tubal rupture but they still account for around $3 \%$ of pregnancy-related deaths in developed countries ${ }^{1,2}$. When ultrasound imaging was first introduced in the diagnosis of TEP at the end of the 1960s, it was just an aid to clinical diagnosis ${ }^{3}$. Over the following three decades, sonographic results were correlated and then progressively integrated with the clinical history and findings as well as with other diagnostic procedures such as culdoscopy and laparoscopy 4 . The advent of transvaginal ultrasound combined with refinements in B-mode and Doppler imaging has further improved noninvasive diagnosis of TEP. This has facilitated development of non-surgical management with ultrasound largely replacing diagnostic laparoscopy as the reference standard for the diagnosis of TEP ${ }^{1}$.

Non-surgical management of non-ruptured TEP include medical treatment with methotrexate and expectant management. Methotrexate was first used in 1965 in the management of an abdominal pregnancy ${ }^{5}$ whereas expectant management has only been offered to women with TEP from the 1980s when ultrasound diagnosis became more sensitive and human chorionic gonadotropin ( $\mathrm{hCG}$ ) radioimmunoassays more widely available ${ }^{6}$. Maternal serum biomarkers and in particular the beta subunit of hCG ( $\beta$-hCG) and progesterone have been pivotal in the development of diagnostic algorithms ${ }^{7,8}$ and follow-up protocols for methotrexate treatment ${ }^{9,10,11}$ and for the expectant management of women presenting with TEP ${ }^{12,13,14}$. Several new biochemical markers and algorithms have been studied over the last decade in an attempt to guide clinicians in the decision-making process. The markers studied include activin $A$, activin $B$, inhibin $A$, follistatin, $A$ disintegrin and metalloprotease-12 (ADAM), pregnancy-associated plasma protein A (PAPPA), pregnancy specific $B_{1}$-glycoprotein ( $\left.\mathrm{SP}_{1}\right)$, interleukins 6 and 8 (IL-6 and IL 8), placental-like growth factor (PGF), vascular endothelial growth factor (VEGF) and glycodelin (Glyc) ${ }^{15,16,17,18,19,20,21}$. The studies investigating their potential diagnostic value are limited by small size, differences in study 
populations and methodology. In addition, the majority of immunoassays for these proteins are not readily available in routine clinical laboratories which also hampered their wider use.

We have previously tested a new clinical protocol for expectant management of TEP, which eliminates the need for medical or surgical treatment in more than a third of all women diagnosed with TEP with a minimum risk of adverse outcomes ${ }^{13}$. We offered expectant management only to clinically stable women with small TEPs on ultrasound scan and low serum $\beta$-hCG. However, despite using these relatively strict selection criteria, expectant management was unsuccessful in $20-25 \%$ of women. The aim of the present study was to evaluate the possible role of selected novel maternal serum biomarkers that are available in routine clinical laboratories in improving the selection of women diagnosed with TEP for successful expectant management.

\subsection{MATERIALS AND METHODS}

In our hospital all pregnant women presenting with bleeding and/or pain in the first trimester of pregnancy are seen in a dedicated Early Pregnancy Assessment Unit (EPAU). They are all examined clinically and most of them undergo a transvaginal ultrasound examination. All examinations are carried out by experienced operators using a high-resolution transvaginal probe (Voluson 730 and E8 Expert, GE Medical Systems, Waukesha, WI, USA). All women who are diagnosed with TEP have a blood sample taken to measure serum $\beta$-hCG and progesterone levels, as well as full blood count and blood group, if required. Additional blood samples were collected as part of an ongoing prospective study protocol on the diagnosis and management of early pregnancy disorders. Maternal serum and plasma were separated and frozen at $-80 \mathrm{C}^{\circ}$ until analysis. Demographic data including maternal age, ethnicity, parity, cigarette smoke exposure, age and body mass index (BMI) were collected at the initial visit. In all women the final pregnancy outcomes were recorded. Expectant management was classified as successful when ectopic pregnancy resolved spontaneously after a period of follow-up without the need for any surgical or medical intervention. 
Patients for the present study were prospectively recruited from a cohort of 533 pregnant women attending the EPAU over an 18 month-period and who all consented take part in the study. The study was approved by the Joint UCL/UCLH Committees on the Ethics of Human Research (Reference Number: 07/Q0512/41). All women received information about the study and written consent was obtained prior to the ultrasound examination. They included 196 women with ongoing intrauterine pregnancies, 177 who were diagnosed with a miscarriage, 67 with pregnancies of unknown location and 93 women diagnosed with TEP. Women with multiple pregnancies and those who were on supplemental hormonal treatment were excluded from the study.

The study group consisted of 93 women diagnosed with TEP during the first trimester of pregnancy. Pregnancies were dated according to the last menstrual period (LMP). Other measurements obtained during the scan and collected for the study were presence of hemoperitoneum (nil/mild/significant), the size (mean diameter) and morphology of TEP (solid/presence of gestational sac/presence of yolk sac/presence of embryo/presence of embryonic cardiac activity) as previously described ${ }^{22}$. Our selection criteria for expectant management have been previously published and they included: clinically stable women with no or minimal abdominal pain, no evidence of significant hemoperitoneum on ultrasound scan, TEP measuring $<30 \mathrm{~mm}$ in mean diameter with no evidence of embryonic cardiac activity and serum $\beta$ hCG $<1500 \mathrm{IU} / \mathrm{L} .{ }^{13}$ Women who did not fulfill the criteria for expectant management were offered surgery. We did not use methotrexate as there is no evidence from randomised trials to show that medical treatment is more effective compared to expectant management ${ }^{23}$.

Women eligible for expectant management $(n=51)$ were then followed-up as previously described ${ }^{13}$. These women were asked to attend the unit at regular intervals for repeat serum $\beta$-hCG measurements. Ultrasound examinations were only performed, if women were in the medical management subgroup 
complained of increased abdominal pain to look for signs of haemoperitoneum and rupture. Follow-up was discontinued when the pregnancy test became negative. Women who underwent surgical management of ectopic pregnancy at follow-up either due to worsening symptoms, rising serum $\beta$-hCG levels or personal choice (e.g. unacceptably long follow-up time) were included in the failed outcome group. In all cases, the pregnancy outcome was confirmed at final follow-up.

\subsection{Bioassays}

All maternal serum samples were assayed for $\beta$-hCG, progesterone, inhibin A, activin A and C-reactive protein (CRP) using commercial assays. Maternal serum progesterone and hCG assays were performed on a Modular E170 Analyzer (Roche Diagnostics, Vilvoorde, Belgium) with an electrochemiluminescence competitive methods. High sensitivity (hs) CRP assay was performed using an immunoturbidimetric method on a Modular $P$ Analyzer (Roche Diagnostics, Vilvoorde, Belgium) with a quantitation limit of $0.5 \mathrm{mg} / \mathrm{L}$. Maternal serum inhibin A and activin A assay was performed on a IMMULITE 2000 immunoassay system (Siemens, Brussels, Belgium) with an enzyme-labeled chemiluminescent immunometric method.

\subsection{Statistical analysis}

The data were analyzed using data analysis and statistical software package Stata 13.1 (StataCorp, Texas, US). Because some distributions were skewed in the sub-groups with an abnormal outcome, data are presented as medians and lower and upper quartiles or interquartile range (IQR). Women who were diagnosed with a TEP were classified as either having successful or failed expectant management of the ectopic pregnancy. Continuous variables were compared between the two groups using Mann-Whitney (Wilcoxon) W rank test at the $95 \%$ confidence interval $(\mathrm{Cl})$. Categorical variables were compared between groups using Fisher's exact test. Individual correlations between the different ultrasound and maternal serum endocrinological variables were calculated in each group by the least square method and their slopes tested for 
significance by the $F$ ratio test. Results were considered statistically significant at $P<0.05$.

A second stage in the analysis considered the joint association between the factors and a successful outcome of expectant management of ectopic pregnancy in a multivariable analysis. Due to the binary nature of the outcome, this analysis was performed using multiple logistic regression. To restrict the number of variables in this stage of the analysis, only factors showing slight association with successful outcome from the initial analyses $(P<0.2)$ were included. A backwards selection procedure was used to retain only the statistically significant variables in the final analysis. This involves removing non-significant variables, one at a time, until all variables were significant. For the second stage of the analysis, continuous variables that had highly positive skewed distributions were analyzed on the log scale (to base 10).

\subsection{RESULTS}

A total of 93 women with a conclusive ultrasound diagnosis of TEP and a full set of data were recruited to the study. Flowchart of participants through the study is shown in Fig. 1. $42 / 93$ (45\%) women were advised to have a surgical management at the initial assessment. The indications for surgery were: moderate to severe lower abdominal pain $(n=6)$, serum $\beta$-hCG $\geq 1,500$ IU $(n=10)$, evidence of a live ectopic pregnancy $(n=5)$ and the presence of significant haemoperitoneum $(n=21)$. The remaining 51/93 (55\%) women were offered expectant management. Among them 42/51 (82\%) had successful expectant management and 9/51(18\%) had surgery after a period of follow up. The indications for interventions were: rising $\beta$-hCG levels in six, worsening symptoms and hemoperitoneum in two, whilst the one remaining woman decided to discontinue conservative treatment and opt for surgery instead.

Data from women who were offered surgery at the initial visit and those who were managed expectantly are shown in Table 1 . The median size of ectopic pregnancy $(P<0.001)$, median serum $\beta$-hCG $(P<0.001)$, inhibin $\mathrm{A}(P<0.001)$ and activin $A(P<0.05)$ levels were all significantly lower in the conservative 
management group. There was a significant positive correlation between gestational age and median serum $\beta$-hCG $(F=6.89 ; r=0.18, P<0.01)$ in the surgical management group. There was no significant correlation between gestational age, size of ectopic pregnancy and other endocrinological parameters in either group. Data form women with successful and failed conservative management are shown in Table 2 . The median serum $\beta$-hCG was significantly lower in the successful compared to the failed conservative management subgroup $(P<0.001)$. There were no significant differences in the size of ectopic pregnancy and other endocrinological parameters.

We also carried out a multivariable analysis. A backwards selection procedure was used to retain only factors showing some suggestion of statistical significance in the final model, which is shown in Table 3. Both mean serum $\beta$ hCG and progesterone were significantly associated with successful outcome of expectant management of TEP $(P<0.05)$. The results for progesterone were only significant after adjusting for $\beta$-hCG. Higher values of both variables were associated with a lower chance of successful expectant management of TEP. A one-unit increase in either variable on the log-scale (equivalent to a 10-fold increase) was associated with an approximate 20 -fold reduction in the odds of a successful outcome.

\subsection{DISCUSSION}

Our study showed that serum $\beta$-hCG and progesterone were significantly different in women with successful and failed expectant management of TEP. In view of that it is very unlikely that addition of Inhibin A, activin A and hcCRP could improve selection of women for conservative management of TEP. Although hsCRP has been successfully used as a biomarker in the diagnosis and management of cardiovascular emergencies such as heart failure and stroke ${ }^{24}$, our data show that it is unlikely to be useful in conservative management of TEP.

The ability to detect small failing TEPs has facilitated development of protocols for conservative management which eliminate the need for surgery and 
hospitalization in a significant number of women. Mishell and Davajan ${ }^{25}$ were the first to use a of urinary assay to determine hCG level in women with complicated early pregnancy. In women with clinical evidence of threatened miscarriage they found that the mean levels of urinary hCG in the patients that miscarriage were consistently lower than those with normal pregnancies. A decade later, Saxena and Landesman ${ }^{26}$, used an $\mathrm{hCG}$ plasma radio receptor assay in 13 women with suspected TEP, one of whom was followed with four separate determinations. They found that in cases of TEP, hCG levels are generally lower than those found in a normal intrauterine pregnancy. Similarly, several authors in the 1970s and 1980s reported on lower serum progesterone levels in women with suspected TEP compared to normal intrauterine pregnancy $y^{27,28,29}$.

We have recently shown in a prospective study of women with a conclusive ultrasound diagnosis of TEP that with the use of strict selection criteria nearly a half of TEP could be managed conservatively with a success rate of $71 \%{ }^{13}$. In the present study, 42 out 51 (82\%) women with a TEP managed conservatively had a successful outcome without the need for a surgical procedure. We found that both Inhibin A and activin A serum levels were lower in the conservative management group compared to the surgical management group and that the decrease in inhibin A was proportionate to the decrease in $\beta$-hCG between the groups. Mean serum $\beta$-hCG in the surgical management group was the only variable positively related with gestational age suggesting that in TEP other endocrinological makers are produced independently of gestational age and gestational sac size. Human placenta, decidua, and fetal membranes are the major sites of production and secretion of inhibin $A$ and activin $A^{30}$. Both have been tested in combination with ultrasound to predict first trimester pregnancy outcome for pregnancy location and viability ${ }^{15,16,17,18,20}$ but never to triage women with conclusive ultrasound diagnosis of TEP.

Expectant management of TEP involves a degree of social disruption with repeated hospital visits to determine serum $\beta$-hCG concentration until the pregnancy test becomes negative and expectant management is considered complete. In a recent study, we found that the maximum serum $\beta$-hCG 
concentration and the rate of decline of $\beta$-hCG were independently associated with the length of follow up and the women's age and the size of TEP did not have significant effects on the length of follow up ${ }^{31}$. No other biomarker has been used in this context, and the results of the present study indicate that progesterone could be considered a promising biomarker along $\beta$-hCG in the prediction of successful expectant management of TEP.

C-reactive protein (CRP) is an acute-phase protein secreted by the liver in response to inflammation ${ }^{32,33}$. One of the first clinical uses of CRP measurements, was for the diagnosis of TEP. Attempts have been made to use CRP for the differential diagnosis between pelvic infection and TEP and between viable intrauterine pregnancy, miscarriage and TEP ${ }^{34,35}$. New sensitive assays are able to measure extremely low concentrations of CRP and are available in most routine and emergency clinical laboratories. There are only a few studies that have evaluated the relationship between hsCRP and first or second trimester pregnancy loss ${ }^{34,36}$. We have also evaluated its role in predicting successful outcome of expectant management in women presenting with missed miscarriage ${ }^{37}$. Similarly to the present study, we found no significant difference in the mean serum hsCRP levels between women with failed and successful conservative management of TEP. Other inflammatory proteins such as cytokines IL-6 and IL-8 have been used for the diagnosis of ruptured TEP ${ }^{21}$ but their use is limited as the corresponding assays are not performed routinely in clinical laboratories.

In our study the trigger for intervention was serum hCG >1500IU/l at presentation or during follow up. This was based on the results of our previous study which showed that more than $70 \%$ of tubal ectopic presenting with serum hCG below that level resolve spontaneously without the need for any medical intervention. If the chosen threshold was different, the proportion of women deemed suitable for expectant management and the success rates would also change. In view of that our findings are not applicable with the use of different hCG cut-offs to trigger active treatment. 
In conclusion, our study has shown that serum hCG and progesterone are currently the only biomarkers that could be used to estimate the likelihood of successful expectant management of TEPs. Future prospective studies are required to investigate this further and determine whether selection criteria for expectant management could be refined to minimise the risk of failure and secondary surgery.

Acknowledgements: The authors wish to thank Mr Paul Bassett (UCLH) for the help with the statistical analysis and the department of clinical chemistry at Hopital Erasme, Université Libre de Bruxelles (ULB) for the laboratory support.

Conflict of interest: None to declare. 


\section{REFERENCES}

1. Knez, J., Day, A., Jurkovic, D. Ultrasound imaging in the management of bleeding and pain in early pregnancy. Best. Pract. Res. Clin. Obstet. Gynaecol. 2014;28:621-636.

2. Creanga, A.A., Syverson, C., Seed, K., Callaghan, W.M. PregnancyRelated Mortality in the United States, 2011-2013. Obstet. Gynecol. 2017;130:366-373.

3. Kobayashi, M., Hellman, L.M., Fillisti, L.P. Ultrasound. An aid in the diagnosis of ectopic pregnancy. Am. J. Obstet. Gynecol. 1969;103:1131-1140.

4. Lurie, S. The history of the diagnosis and treatment of ectopic pregnancy: a medical adventure. Eur. J. Obstet. Gynecol. Reprod. Biol. 1992;43:1-7.

5. Hreshchyshyn, M.M., Naples, J.D., Randall, C.L. Amethopterin in abdominal pregnancy. Am. J. Obstet. Gynecol. 1965;93:286-287.

6. De Cherney, A.H., Minkin, M.J., Spangler, S. Contempory management of ectopic pregnancy. J Reprod. Med. 1981;26:519-523.

7. Day, A., Sawyer, E., Mavrelos, D., Tailor, A., Helmy, S., Jurkovic, D. Use of serum progesterone measurements to reduce need for followup in women with pregnancies of unknown location. Ultrasound Obstet. Gynecol. 2009;33:704-710.

8. Odejinmi, F., Huff, K.O., Oliver, R. Individualisation of intervention for tubal ectopic pregnancy: historical perspectives and the modern evidence based management of ectopic pregnancy. Eur. J. Obstet. Gynecol. Reprod. Biol. 2017;210:69-75.

9. Saraj, A.J., Wilcox, J.G., Najmabadi, S., Stein, S.M., Johnson, M.B., Paulson, R.J. Resolution of hormonal markers of ectopic gestation: a randomized trial comparing single-dose intramuscular methotrexate with salpingostomy. Obstet. Gynecol. 1998;92:989-994.

10.Wu, J., Ludlow, J.P., De Vries, B., Black, K., Beale, P. Single-dose methotrexate treatment for ectopic pregnancy and pregnancy of unknown location and progesterone as a predictor of success. Aust. N. Z. J. Obstet. Gynaecol. 2014;54:469-474.

11. Kovaleva, A., Irishina, N., Pereira, A., Cuesta-Guardiola, T., OrtizQuintana, L. Methotrexate-treated ectopic pregnancy: beta human chorionic gonadotropin serum changes as a success predictor using a mathematical model validation. Eur. J. Obstet. Gynecol. Reprod. Biol. 2017;210:35-38.

12. Adoni, A., Milwidsky, A., Hurwitz, A., Palti, Z. Declining beta-HCG levels: an indicator for expectant approach in ectopic pregnancy. Int. J. Fertil. 1986;31:40-42.

13. Mavrelos, D., Nicks, H., Jamil, A., Hoo, W., Jauniaux, E., Jurkovic, D. 
Efficacy and safety of a clinical protocol for expectant management of selected women diagnosed with a tubal ectopic pregnancy. Ultrasound Obstet. Gynecol. 2013;42:102-107.

14. Helmy, S., Mavrelos, D., Sawyer, E., Ben-Nagi, J., Koch, M., Day, A., Jurkovic, D. Serum human Chorionic Gonadotropin ( $\beta$ - hCG) clearance curves in women with successfully expectantly managed tubal ectopic pregnancies: A retrospective cohort study. PLoS One 2015;10:e0130598.

15. Florio, P., Reis, F.M., Battista, R., Luisi, S., Moncini, I., Bocchi, C., Severi, F.M., Petraglia, F. Serum activin A levels are lower in tubal than intrauterine spontaneously conceived pregnancies. Gynecol. Endocrinol. 2011;27:391-395.

16. Rausch, M.E., Sammel, M.D., Takacs, P., Chung, K., Shaunik, A., Barnhart, K.T. Development of a multiple marker test for ectopic pregnancy. Obstet. Gynecol. 2011;117:573-582.

17. Warrick, J., Gronowski, A., Moffett, C., Zhao, Q., Bishop, E., Woodworth, A. Serum activin A does not predict ectopic pregnancy as a single measurement test, alone or as part of a multi-marker panel including progesterone and hCG. Clin. Chim. Acta 2012;413:707-711.

18. Daponte, A., Deligeoroglou, E., Garas, A., Pournaras, S., Hadjichristodoulou, C., Messinis, I,E. Activin A and follistatin as biomarkers for ectopic pregnancy and missed abortion. Dis, Markers 2013;35:497-503.

19. Senapati, S., Sammel, M.D., Butts, S.F., Takacs, P., Chung, K., Barnhart, K.T. Predicting first trimester pregnancy outcome: derivation of a multiple marker test. Fertil. Steril. 2016;106:1725-1732.

20. Dhiman, P., Senthilkumar, G.P., Rajendiran, S,, Sivaraman, K., Soundararaghavan, S., Kulandhasamy, M. Serum activin B concentration as predictive biomarker for ectopic pregnancy. Clin. Biochem. 2016;49:609-612.

21. Rajendiran, S., Senthil Kumar, G.P., Nimesh, A., Dhiman, P., Shivaraman, K., Soundararaghavan, S. Diagnostic significance of IL-6 and IL-8 in tubal ectopic pregnancy. J. Obstet. Gynaecol .2016;36:909911.

22. Rajah, K., Goodhart, V., Zamora, K.P., Amin, T., Jauniaux, E., Jurkovic, D. How to Measure Size of Tubal Ectopic Pregnancy on Ultrasound Scan? Ultrasound Obstet. Gynecol. 2018;52:103-109.

23. National Institute for Health and Care Excellence. Ectopic pregnancy and miscarriage: diagnosis and initial management (NICE Guideline 126). 2019. Available at https://www.nice.org.uk/guidance/ng126 [Accessed on 24 March 2020]

24. Magnussen, C., Blankenberg, S. Biomarkers for heart failure: small 
molecules with high clinical relevance. J. Intern. Med. 2018;283:530543.

25. Mishell, D.R. Jr, Davajan, V. Quantitative immunologic assay of human chorionic gonadotropin in normal and abnormal pregnancies. Am. J. Obstet. Gynecol. 1966;96:231-239.

26. Saxena, B.B., Landesman, R. The use of a radio receptor assay of human chorionic gonadotropin for the diagnosis and management of ectopic pregnancy. Fertil. Steril. 1975;26:397-404.

27. Radwanska, E., Frankenberg, J., Allen, E.I. Plasma progesterone levels in normal and abnormal early human pregnancy. Fertil. Steril. 1978;30:398-402.

28. Matthews, C.P., Coulson, P.B., Wild, R.A. Serum progesterone levels as an aid in the diagnosis of ectopic pregnancy. Obstet. Gynecol. 1986;68:390-394.

29. Hubinont. C.J., Thomas, C., Schwers, J.F. Luteal function in ectopic pregnancy. Am. J. Obstet. Gynecol. 1987;156:669-674.

30. Muttukrishna, S., Child, T.J., Groome, N.P., Ledger, W.L. Source of circulating levels of inhibin A, pro alpha C-containing inhibins and activin A in early pregnancy. Hum. Reprod. 1997;12:1089-1093.

31. Mavrelos, D., Memtsa, M., Helmy, S., Derdelis, G., Jauniaux, E., Jurkovic, D. $\beta$-hCG resolution times during expectant management of tubal ectopic pregnancies. BMC. Womens Health 2015;15:43.

32. Mutafian, R.I, Babakhanian, G.G., Chkhikvadze, R.A. C-reactive protein reaction as a new test in diagnosis of extrauterine pregnancy. Zh. Eksp. Klin. Med. 1966;6:50-55.

33. Theron, G,B,, Shepherd, E.G., Strachan, A.F. C-reactive protein levels in ectopic pregnancy, pelvic infection and carcinoma of the cervix. $S$. Afr. Med. J. 1986;69:681-682.

34. Boggess, K.A., Lieff, S., Murtha, A.P., Moss, K., Jared, H., Beck, J., Offenbacher, $S$. Maternal serum C-reactive protein concentration early in pregnancy and subsequent pregnancy loss. Am. J. Perinatol. 2005;22:299-304.

35. Cohen, Y., Ascher-Landsberg. J., Cohen, A., Lessing, J.B., Grisaru, D. The role of C-reactive protein measurement as a diagnostic aid in early pregnancy. Eur. J. Obstet. Gynecol. Reprod. Biol .2014;176:6467.

36. Jauniaux, E., Gulbis, B., Jamil, A., Jurkovic, D. Evaluation of the role of maternal serum high-sensitivity C-reactive protein in predicting early pregnancy failure. Reprod. Biomed. Online 2015;30:268-274.

37. Memtsa, M., Jauniaux, E., Gulbis, B., Nyrhinen, N.C, Jurkovic, D. Maternal serum markers in predicting successful outcome in expectant management of missed miscarriage. Reprod. Biomed. Online 2017;34:98-103. 
Table 1. Comparison of the different ultrasound and endocrinological variable in the surgical $(n=42)$ and conservative $(n=51)$ management groups. Data are presented as mean \pm standard deviation or median [inter-quartile range].

\begin{tabular}{|l|c|c|c|}
\hline Variable & $\begin{array}{c}\text { Surgical } \\
(\mathrm{n}=42)\end{array}$ & $\begin{array}{c}\text { Conservative } \\
(\mathrm{n}=51)\end{array}$ & P-value \\
\hline Gestational age (days) & $52 \pm 15$ & $48 \pm 10$ & 0.12 \\
Sac diameter $(\mathrm{mm})$ & $17.8 \pm 6.5$ & $13.7 \pm 4.1$ & $<0.001$ \\
$\beta$-hCG $(\mathrm{U} / \mathrm{L})$ & $2074[830 ; 4985]$ & $429[204 ; 880]$ & $<0.001$ \\
Progesterone $(\mathrm{nmol} / \mathrm{L})$ & $20.5[8.0 ; 30.5]$ & $13.3[6.4 ; 29.5]$ & 0.37 \\
Inhibin $(\mathrm{pg} / \mathrm{ml})$ & $16.4[9.9 ; 60.5]$ & $3.9[3.9 ; 28.8]$ & $<0.001$ \\
Activin $(\mathrm{pg} / \mathrm{ml})$ & $895[622 ; 1275]$ & $710[78 ; 1113]$ & 0.03 \\
\hline
\end{tabular}


Table 2: Results of the univariable analysis of the different variables investigated in failed $(n=9)$ and successful $(n=42)$ expectant management subgroups. Data are presented as mean \pm standard deviation, median [interquartile range], or number (percentage).

\begin{tabular}{|l|c|c|c|}
\hline Variable & Failed $(\mathrm{n}=9)$ & Success $(\mathrm{n}=42)$ & P-value \\
\hline Maternal age & $33.2 \pm 6.9$ & $32.2 \pm 5.9$ & 0.65 \\
Symptoms - Bleeding & $3(33 \%)$ & $15(36 \%)$ & 1.00 \\
- Mild pain & $0(0 \%)$ & $2(5 \%)$ & \\
and bleeding & $5(56 \%)$ & $21(51 \%)$ & \\
- Other & $1(11 \%)$ & $3(7 \%)$ & \\
Size (mm) & $13.1 \pm 3.6$ & $13.8 \pm 4.2$ & 0.66 \\
hCG & $1173[863,1801]$ & $386[182,570]$ & 0.005 \\
Progesterone & $17.0[11.6,28.4]$ & $12.5[4.6,29.5]$ & 0.15 \\
Presence of gestational & $4(44 \%)$ & $16(38 \%)$ & 0.72 \\
sac & & & \\
Inhibin (pg/ml) & $3.9[3.9,57.5]$ & $3.9[3.9,27.3]$ & 0.71 \\
Activin (pg/ml) & $708[78,961]$ & $712[78,1159]$ & 0.70 \\
hsCRP (mg/dl) & $0.05[0.05,0.25]$ & $0.09[0.05,0.20]$ & 0.69 \\
\hline
\end{tabular}


Table 3: Significant results of multivariate analysis in successful expectant management.

\begin{tabular}{|l|c|c|}
\hline Variable (maternal serum) & Odds Ratio $(95 \% \mathrm{Cl})$ & P-value \\
\hline$\beta_{\text {-hCG }}^{(+)}$ & $0.06(0.00,0.63)$ & 0.02 \\
Progesterone $^{(+)}$ & $0.05(0.00,0.63)$ & 0.02 \\
\hline
\end{tabular}

$(+)$ Variable analysed on the log scale (to base 10) 